\title{
The impact of multifocal intraocular lens in retinal imaging with optical coherence tomography
}

\author{
Arnaldo Dias-Santos 1 , Lívio Costa', Vanessa Lemos¹, Rita Anjos 1 , André Vicente ${ }^{1}$, \\ Joana Ferreira², João Paulo Cunha ${ }^{3}$ \\ ${ }^{1}$ Interno do Internato Complementar em Oftalmologia no Centro Hospitalar de Lisboa Central \\ ${ }^{2}$ Assistente Hospitalar de Oftalmologia no Centro Hospitalar de Lisboa Central \\ ${ }^{3}$ Assistente Hospitalar Sénior de Oftalmologia no Centro Hospitalar de Lisboa Central
}

\section{RESUMO}

Introdução: As lentes intraoculares multifocais (LIOs MF) têm óticas com vários anéis concêntricos com diferentes potências dióptricas, permitindo uma boa acuidade visual em várias distâncias focais. No entanto, tal design associa-se a algumas limitações óticas. O objetivo deste estudo é avaliar o impacto das LIOs MF na precisão e qualidade das imagens de tomografia de coerência ótica (OCT).

Material e Métodos: Estudo transversal com 23 olhos de 15 doentes com LIO MF e 27 olhos de 15 doentes com LIO monofocal asférica. Todos os doentes realizaram OCT macular utilizando o Heidelberg Spectralis ${ }^{\circledR}$. Avaliaram-se os valores de espessura e volume maculares em 3 áreas concêntricas centradas na fóvea: zona central $(1 \mathrm{~mm})$, zona parafoveal $(2 \mathrm{~mm})$ e zona perifoveal (3 mm). Estes parâmetros, bem como a qualidade de imagem (fator Q), foram comparados entre os dois grupos de estudo.

Resultados: Não se verificaram diferenças estatisticamente significativas entre os dois grupos relativamente à espessura ou volume maculares $(p>0,01)$. A qualidade média das imagens do OCT macular (fator Q) foi de 23,13 dB no grupo das LIOs MF e 26,84 dB no grupo das LIOs monofocais. Esta diferença foi estatisticamente significativa $(p=0.003)$.

Conclusões: As LIOs MF condicionam uma diminuição significativa na qualidade da imagem de OCT. No entanto, este facto não parece comprometer a precisão das medições retinianas realizadas com este método de imagem.

\section{Palavras chave}

Espessura macular; lente intraocular multifocal; qualidade de imagem; tomografia de coerência ótica.

\footnotetext{
ABSTRACT

Introduction: Multifocal intraocular lenses (MF IOLs) have concentric optical zones with different dioptric power, enabling patients to have good visual acuity at multiple focal points. However, several optical limitations have been attributed to this particular design. The purpose of this study is to access the effect of MF IOLs design on the accuracy of retinal optical coherence tomography (OCT).

Material and Methods: Cross-sectional study with 23 eyes of 15 patients with a diffractive MF IOL and 27 eyes of 15 patients with an aspheric monofocal IOL. All patients underwent
} 
OCT macular scans using Heidelberg Spectralis ${ }^{\circledR}$. Macular thickness and volume values were evaluated in three concentric zones centered on the foveal center: central $(1 \mathrm{~mm})$, parafoveal (2 $\mathrm{mm}$ ) and perifoveal $(3 \mathrm{~mm})$. These parameters, as well as retinal image quality (Q factor) were compared between the two groups.

Results: There were no statistically significant differences between both groups regarding macular thickness or volume measurements. The mean Q factor was 23.13 dB in the MF IOL group and $26.84 \mathrm{~dB}$ in the monofocal group. This difference was statistically significant $(\mathrm{p}=0.003)$.

Conclusion: MF IOLs are associated with a significant decrease in OCT image quality. However, this fact does not seem to compromise the accuracy of OCT retinal measurements.

\section{Key-words}

Image quality; macular thickness; multifocal intraocular lens; optical coherence tomography.

\section{INTRODUCTION}

Cataract surgery has evolved from a visual rehabilitating procedure to become a refractive surgery in which the independence of corrective lenses is seen as a criterion of quality and satisfaction ${ }^{1}$. In this regard, monofocal intraocular lens (IOL) usually provides excellent visual function, however its limited depth of focus does not allow simultaneous clear vision for both distance and near. On the other hand, multifocal (MF) IOLs have multiple focal lengths within the optical zone, which results in a more acceptable range of near through distance vision as well as increased spectacle independence ${ }^{2,3}$. Consequently MF IOLs are becoming an increasingly popular option for the correction of presbyopia. Although eyes with ophthalmic pathology such as vitreoretinal diseases or glaucoma are not candidates for implantation of a MF IOL, the incidence of these pathologies in patients with previously implanted MF IOLs will probably rise given the increasing popularity of this type of lens.

Optical coherence tomography (OCT) has assumed a major role in the study of retinal and optic nerve pathology in the last years. However, to date very few studies evaluated the effect of MF IOLs design on the accuracy of retinal imaging and measurements performed by OCT devices. The objective of this study is to compare retinal OCT measurements in patients with two different types of diffractive MF IOLs with a control group with monofocal aspheric IOLs.

\section{MATERIAL AND METHODS}

Cross-sectional study conducted at a university based tertiary centre. Twenty-three eyes of fifteen patients who underwent uneventful phacoemulsification with implantation of Acrysof ReSTOR SA60D3 apodized diffractive multifocal
IOL (Alcon Laboratories) or Tecnis ZM900 aspheric diffractive multifocal IOL (Abbott Medical Optics) were enrolled in this study. Twenty-seven eyes of fifteen patients who underwent uneventful phacoemulsification with monofocal aspheric IOL implantation, either Acrysof IQ SN60WF (Alcon Laboratories) or Tecnis ZCB00 (Abbott Medical Optics) served as a control group. All eyes enrolled in the study had a post-operative follow-up superior to one month. Eyes with posterior capsular opacity, corneal or vitreoretinal pathologies, ocular hypertension, optic neuropathies, pre-operative spherical equivalent higher than $\pm 6.0 \mathrm{D}$ or astigmatism higher than $\pm 3.0 \mathrm{D}$ were excluded from the study. Written, informed consent was obtained from all subjects and this investigation adhered to the tenets of the Declaration of Helsinki. Ethics Committee approval was obtained.

Every patient was submitted to a complete ophthalmological evaluation that included best corrected visual acuity (BCVA) assessment, refraction, biomicroscopy, fundoscopy, Goldmann applanation tonometry, and macular imaging using OCT Heidelberg Spectralis ${ }^{\circledR}$ (Heidelberg Engineering, Heidelberg, Germany). Twenty-five sections, each comprising 100 averaged scans, were obtained in a $20^{\circ} \times 20^{\circ}$ $(5.8 \mathrm{~mm} \times 5.8 \mathrm{~mm})$ square centered on the fovea. Macular thickness and volume parameters were automatically calculated by existing Heidelberg OCT software (version 5.3.2). Three concentric zones centered on the foveal center were evaluated and compared between the two study groups: central $(1 \mathrm{~mm})$, parafoveal $(2 \mathrm{~mm})$ and perifoveal $(3 \mathrm{~mm})$ (figure 1). The Q factor - a measure of OCT signal strength - was also obtained and compared between both groups.

The data was statistically analysed using SPSS for Windows, version 20.0; IBM/SPSS, Chicago, IL. Student's $t$ test was performed to compare the mean differences between continuous variables, with a $\mathrm{p}$ value of 0.01 being considered as statistically significant. 

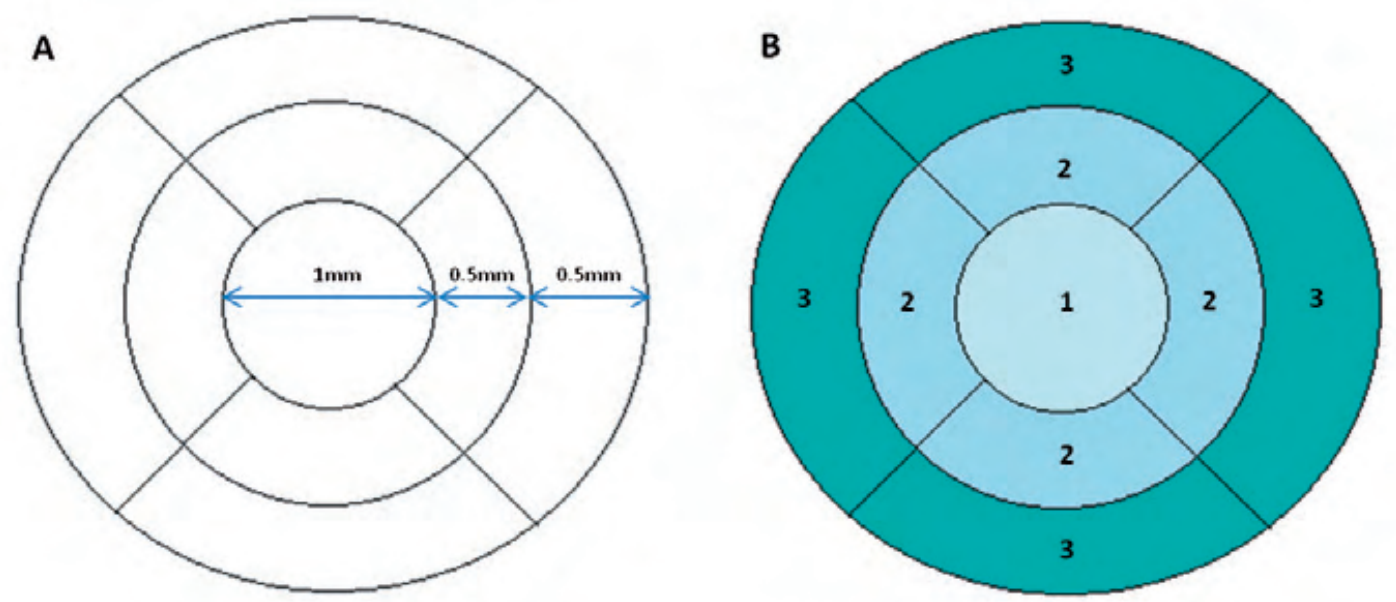

Fig. 1 Diagrammatic representation of the different concentric macular areas analyzed in the study: central (zone 1), parafoveal (zone 2) and perifoveal (zone 3).

\section{RESULTS}

In the MF IOL group we studied 23 eyes of 15 patients (4 men and 11 women); in the monofocal IOL group we studied 27 eyes of 15 patients ( 3 men and 12 women). Table 1 presents the parameters analyzed in this study. There were no statistically significant differences between both groups regarding age, postoperative distance BCVA and axial length. The mean postoperative refractive cylinder was $0.72 \pm 0.46 \mathrm{D}$ in the MF IOL group and $0.83 \pm 0.48 \mathrm{D}$ in the monofocal IOL group $(\mathrm{p}=0.223)$. The mean macular thickness in zone 1 in the MF IOL group was $280.00 \mu \mathrm{m}$ and in the monofocal group it was $283.00 \mu \mathrm{m}(\mathrm{p}=0.373)$; the mean macular thickness in zone 2 in the MF IOL group was $331.60 \mu \mathrm{m}$ and in the monofocal group it was 334.68 $\mu \mathrm{m}(\mathrm{p}=0.372)$; the mean macular thickness in zone 3 in the MF IOL group was $337.35 \mu \mathrm{m}$ and in the monofocal group it was $336.20 \mu \mathrm{m}(\mathrm{p}=0.453)$. The mean macular volume in zone 1 in the MF IOL group was $0.22 \mathrm{~mm} 3$ and in the monofocal group it was $0.22 \mathrm{~mm} 3(\mathrm{p}=0.388)$; the mean macular volume in zone 2 in the MF IOL group was $0.21 \mathrm{~mm} 3$ and in the monofocal group it was $0.20 \mathrm{~mm} 3(\mathrm{p}=0.221)$; the

Table 1 Patients' age, postoperative distance best corrected visual acuity (BCVA), axial length, postoperative refractive cylinder, type of implanted intraocular lens (IOL) and optical coherence tomography parameters. *Statistically significant difference between both groups

\begin{tabular}{|c|c|c|c|}
\hline Parameter & MF IOL & Monofocal IOL & p value \\
\hline IOL type & 9 AcrySof ReSTOR SA60D3/ & 12 Acrysof IQ SN60WF/ & ---- \\
\hline & 14 Tecnis Multifocal ZMB00 & 15 Tecnis ZCB00 & \\
\hline Age (years) & $68.80 \pm 11.74$ & $76.07 \pm 7.16$ & 0.025 \\
\hline Postoperative distance BCVA & $0.93 \pm 0.11$ & $0.93 \pm 0.10$ & 0.389 \\
\hline Axial length (mm) & $22.57 \pm 1.44$ & $22.90 \pm 1.11$ & 0.196 \\
\hline Postoperative astigmatism (D) & $0.72 \pm 0.46$ & $0.83 \pm 0.48$ & 0.223 \\
\hline Macular thickness in zone $1(\mu \mathrm{m})$ & $280.00 \pm 29.80$ & $283.00 \pm 33.17$ & 0.373 \\
\hline Macular thickness in zone $2(\mu \mathrm{m})$ & $331.60 \pm 26.34$ & $334.68 \pm 36.66$ & 0.372 \\
\hline Macular thickness in zone $3(\mu \mathrm{m})$ & $337.35 \pm 34.27$ & $336.20 \pm 32.81$ & 0.453 \\
\hline Macular volume in zone $1(\mathrm{~mm} 3)$ & $0.22 \pm 0.02$ & $0.22 \pm 0.03$ & 0.388 \\
\hline Macular volume in zone $2(\mathrm{~mm} 3)$ & $0.21 \pm 0.06$ & $0.20 \pm 0.02$ & 0.221 \\
\hline Macular volume in zone $3(\mathrm{~mm} 3)$ & $0.38 \pm 0.22$ & $0.33 \pm 0.03$ & 0.141 \\
\hline$Q$ factor $(d B)$ & $23.13 \pm 5.24$ & $26.84 \pm 3.44$ & $0.003^{*}$ \\
\hline
\end{tabular}


mean macular volume in zone 3 in the MF IOL group was $0.38 \mathrm{~mm} 3$ and in the monofocal group it was $0.33 \mathrm{~mm} 3$ $(\mathrm{p}=0.141)$. Thus, OCT analysis did not reveal significant differences in macular thickness or macular volume measurements in any of the macular zones analyzed. The mean Q factor was $23.13 \mathrm{~dB}$ in the MF IOL group and $26.84 \mathrm{~dB}$ in the monofocal group $(\mathrm{p}=0.003)$. The $\mathrm{Q}$ factor was significantly higher in the monofocal IOL group, indicating better image quality in this group.

No wavy horizontal artifacts were seen in OCT images or in confocal scanning-laser ophthalmoscopy images in both groups.

\section{DISCUSSION}

This study demonstrates that OCT measurements in the macular area are not affected by the optical design of diffractive MF IOLs. These measurements were comparable to those performed in patients implanted with monofocal aspheric IOL. However, MF IOL reduces OCT image quality by more than $3 \mathrm{~dB}$. This reduction was statistically significant.

MF IOLs provide good distance and near visual acuity, being a good solution for implantation following cataract surgery as well as following refractive lens exchange ${ }^{4-7}$. Diffractive MF IOLs have concentric optical zones with different dioptric power, enabling patients to have good visual acuity at multiple focal points ${ }^{3}$. The drawbacks associated with this type of IOL design are loss of contrast sensitivity, increase in higher order aberrations and night-time glare and halos ${ }^{8,9}$. Aychoua et al recently reported a clinically relevant reduction of visual sensitivity as assessed with standard automated perimetry in patients with $\mathrm{MF} \mathrm{IOL}^{10}$. Another published paper reported wavy horizontal artifacts on OCT line-scanning ophthalmoscopy images in patients with two different types of diffractive MF IOLs, tested with 4000 Cirrus HD-OCT ${ }^{\circledR}$ device (Carl Zeiss Meditec). The authors however found no differences in retinal thickness, retinal volume or fundoscopic photographs ${ }^{11}$. Skiadaresi et al evaluated retinal measurements following implantation of LENTIS Mplus, an asymmetrically powered refractive MF IOL, with a surface-embedded section for near vision that occupies only a segment of the optic. In this study, the authors used Topcon 3D OCT $1000^{\circledR}$ (Topcon, Oakland, NJ) and found neither image artifacts nor alterations in retinal thickness or volume measurements ${ }^{12}$. It has also been reported a decrease in OCT signal strength and image quality ( $\mathrm{Q}$ factor) in patients with multifocal contact lenses, which was found to reduce more with increased reading add of the multifocal contact lens ${ }^{13}$. Our study, as far as we know, is the first to demonstrate a decrease in OCT signal strength in patients with diffractive MF IOLs. We also accessed the impact of this IOL design in retinal imaging using another OCT device, Heidelberg Spectralis ${ }^{\circledR}$. To test if the optical rings with different dioptric power have influence in retinal measurements we evaluated the average thickness and volume in three concentric macular regions in patients with diffractive MF IOL and compared with patients implanted with monofocal IOL. In accordance to the previous studies on diffractive and refractive MF IOLs, we found no significant changes in retinal measurements ${ }^{11,12}$. However, contrary to a previous work on diffractive MF IOLs ${ }^{11}$, we found no artifacts on fundoscopic images captured by the OCT device. This fact is probably related to different OCT device technology. The 4000 Cirrus $\mathrm{HD}-\mathrm{OCT}^{\circledR}$ device uses a line-scanning ophthalmoscopy system based on a "semi" confocal principle, which produces horizontal artifacts in eyes with diffractive MF IOLs ${ }^{14}$. On the other hand, the Heidelberg Spectralis ${ }^{\circledR}$ OCT, utilized in our study, uses a scanning-laser ophthalmoscopy system, which produces confocal imaging. A confocal system uses a pinhole to remove light from adjacent voxels in order to improve the image details, while a flying-spot camera scans a focused spot in one dimension with a high-speed optical element ${ }^{11}$. Therefore, scanning-laser ophthalmoscopy generates no artifacts in eyes with diffractive MF IOLs.

It is important to note that there is a slight difference regarding the mean age of the two study groups, which was higher in the monofocal IOL group. This difference, however, did not reach the threshold for statistical significance adopted in this study. Taking into account the highly significant difference in retinal image quality between the two groups $(p<0.01)$, we believe that this fact does not compromise the major conclusions of this study. Moreover, previous studies suggest that increasing age can have a negative impact in OCT image quality in phakic patients ${ }^{15}$, but to date there are no studies evaluating the effect of age in OCT image quality in pseudophakic patients.

In conclusion, the optical design of diffractive MF IOLs may affect OCT imaging by reducing signal strength and image quality. However, this finding does not seem to impair the potential of this important diagnostic tool in the diagnosis and follow-up of vitreoretinal disorders.

\section{REFERENCES}

1. Packer M, Fine IH, Hoffman RS (2008) Aspheric intraocular lens selection: the evolution of refractive cataract surgery. Curr Opin Ophthalmol 19(1):1-4. 
2. Alfonso JF, Fernández-Vega L, Baamonde MB, Montés-Micó R (2007) Prospective visual evaluation of apodized diffractive intraocular lenses. J Cataract Refract Surg 33(7):1235-1243.

3. Gierek-Ciaciura S, Cwalina L, Bednarski L, Mrukwa-Kominek E (2010) A comparative clinical study of the visual results between three types of multifocal lenses. Graefes Arch Clin Exp Ophthalmol 248:133-140.

4. Steinert RF (2000) Visual outcomes with multifocal intraocular lenses. Curr Opin Ophthalmol 11(1):12-21.

5. Fine IH, Hoffman RS, Packer M (2007) Refractive lens exchange: the quadruple win and current perspectives. J Refract Surg 23:819-824.

6. Fernández-Vega L, Alfonso JF, Rodríguez PP, Montés-Micó R (2007) Clear lens extraction with multifocal apodized diffractive intraocular lens implantation. Ophthalmology 114:1491-1498.

7. Charman WN, Montés-Micó R, Radhakrishnan $\mathrm{H}$ (2008) Problems in the measurement of wavefront aberration for eyes implanted with diffractive bifocal and multifocal intraocular lenses. J Refract Surg 24:280-286.

8. de Vries NE, Webers CA, Touwslager WR, Bauer NJ, de Brabander J, Berendschot TT, Nuijts RM (2011) Dissatisfaction after implantation of multifocal intraocular lenses. J Cataract Refract Surg 37(5):859-865.

9. Blaylock JF, Si Z, Vickers C (2006) Visual and refractive status at different focal distances after implantation of the ReSTOR multifocal intraocular lens. J Refract Surg 32(9):1464-1473.

10. Aychoua N, Junoy Montolio FG, Jansonius NM (2013) Influence of multifocal intraocular lenses on standard automated perimetry test results. JAMA Ophthalmol 131(4):481-5.
11. Inoue M, Bissen-Miyajima H, Yoshino M, Suzuki T (2009) Wavy horizontal artifacts on optical coherence tomography line-scanning images caused by diffractive multifocal intraocular lenses. J Cataract Refract Surg 35(7):1239-43

12. Skiadaresi E, McAlinden C, Ravalico G, Moore J (2012) Optical coherence tomography measurements with the LENTIS Mplus multifocal intraocular lens. Graefes Arch Clin Exp Ophthalmol 250(9):1395-8.

13. Posner M, Naroo SA, Nithyanandarajah G, Trivedy M, Sharma A (2010) Multifocal contact lenses and posterior pole imaging. Cont Lens Anterior Eye 33(3):151.

14. Hammer DX, Ferguson RD, Ustun TE, Bigelow CE, Iftimia NV, Webb RH (2006) Line-scanning laser ophthalmoscope. J Biomed Opt 11(4):041126.

15. Na JH, Sung KR, Lee Y (2012) Factors associated with the signal strengths obtained by spectral domain optical coherence tomography. Korean J Ophthalmol 26(3):169-73.

Trabalho desenvolvido no Serviço de Oftalmologia do Centro Hospitalar de Lisboa Central

Diretor de Serviço: Dr. Miguel Trigo

Hospital de Santo António dos Capuchos, Serviço de Oftalmologia,

Alameda de Santo António dos Capuchos, 1169-050 Lisboa.

Os autores não têm conflitos de interesse a declarar.

\section{CONTACTO}

Arnaldo Dias-Santos,

Tlm: 919273677

Email: arnaldomiguelsantos@gmail.com 